\title{
中国旅游业碳均衡区域差异及其影响因素
}

\author{
王峥, 程锦红, 程占红* \\ 山西财经大学文化旅游学院,太原 030031
}

\begin{abstract}
摘要:碳均衡分析是新时期旅游业绿色、低碳发展的重要研究方向之一。立足 “源-汇” 视角,运用旅游碳赤字测度模型和 Theil 指数研究了 2008-2017 年中国旅游业碳均衡状态及其区域差异,并基于 K-means cluster 和典范对应分析方法探究了各省域碳 均衡分布与影响因子之间的关系。结果表明: 研究期内中国旅游业碳排放远高于碳承载力, 导致旅游碳赤字均值由 515 万 $\mathrm{t}$ 上 升至 1358 万 $\mathrm{t}$, 旅游业发展始终处于碳失衡状态; Theil 指数的结果进一步反映了旅游碳赤字存在区域差异性, 这种差异主要源 于地带内差异, 而地带内差异主要是由东部和西部地带内的差异引起的; 各省域可以分为旅游业碳排放最低型、旅游碳承载力 最高型、旅游碳赤字较高型、旅游碳赤字最高型四类; 结合 K-means cluster 和典范对应分析的结果可以识别出影响碳均衡状态 的正负向因子,并为实现各区域旅游业碳均衡指明了差异化的发展路径。
\end{abstract}

关键词: 旅游业碳均衡; 旅游碳赤字;Theil 指数;典范对应分析

\section{Regional differences and influencing factors of tourism carbon equilibrium in China}

WANG Zheng, CHENG Jinhong, CHENG Zhanhong*

College of Culture Tourism, Shanxi University of Finance and Economics, Taiyuan 030031, China

Abstract: It is an important direction for green and low-carbon development to study carbon equilibrium of the tourism industry in the new era. Based on the perspective of "source-sink", tourism carbon equilibrium status and regional differences were studied by tourism carbon deficit measurement model and Theil index in China from 2008 to 2017. relationship between the provincial carbon equilibrium distribution and the influencing factors was explored by the K-means cluster and canonical correspondence analysis (CCA). The results showed that: (1) The carbon emission of China's tourism industry was much higher than the carbon capacity of the ecosystem during 2008 to 2017, resulting in the average carbon deficit of tourism rising from 5.15 million tons to 13.58 million tons, and tourism industry has always been in a carbon imbalance. (2) The regional differences were presented by the results of Theil index in tourism carbon deficit, which were mainly due to intra-regional differences, while intra-regional differences were mainly caused by differences in the eastern and western regions. (3) Based on the differences of evaluation indices, various provinces could be divided into four types: the least type of tourism emissions, the most type of tourism carbon capacity, the more type of tourism carbon deficit, and the most type of tourism carbon deficit. Degree of tourism carbon imbalance was relatively weaker in the first two groups, in which most of the provinces were in a general state of carbon imbalance. While the latter two groups generally showed a serious carbon imbalance, and the situation of emission reduction of provincial tourism was not optimistic in these groups. (4) From the lower left corner to the upper right corner of the canonical correspondence analysis figure, four groups were

基金项目: 国家自然科学基金项目 (41571141); 山西省哲学社会科学规划课题 (2020YY118); 山西省研究生教育改革研究项目 (2019JG129, 2020YJJG168)

收稿日期: 2020-09-03; 采用日期: 2021-03-01

*通讯作者 Corresponding author.E-mail: chengzhanhong@163.com 
transited gradually from a general carbon imbalance type area to a severe carbon imbalance type area. (5) The principal factors affecting the change of tourism carbon equilibrium could be identified by the canonical correspondence analysis method, such as tourism reception scale, tourism economic scale, tourism technology level, land use structure, and so on. Based on the heterogeneous spatial effect of various factors on the carbon equilibrium of tourism, the low-carbon development path of regional differentiation is pointed out.

Key Words : tourism carbon equilibrium; tourism carbon deficit; Theil index; canonical correspondence analysis

进入新世纪以来, 全球变暖形势不断加剧, “节能减排”、“绿色可持续”成为国际社会普遍关注的热点话 题。2016 年, 170 多个国家共同签署《巴黎协定》,奠定了世界各国广泛参与碳减排的基本格局,传递出了全 球将实现绿色低碳和可持续发展的强有力积极信号。在此背景下, 每个企业、部门或产业都应积极构筑气候 适应型的绿色低碳发展模式,旅游业也不例外。据统计,旅游业对全球温室气体排放的贡献约为 $8 \%$,远超许 多其他经济部门 ${ }^{[1]}$ 。作为全球最大的国内旅游市场, 中国旅游业的减排工作尤为紧迫。2018 年, 全国接待海 内外游客数量近 57 亿人次, 如此庞大的旅游规模势必会带来大量的能源消耗及碳排放, 对生态环境也会造成 一系列的负面效应。因此,协调旅游经济发展与生态环境的平衡关系, 促进旅游业绿色、低碳转型, 将是新时 期旅游研究的重要内容。

评估旅游业能耗及碳排放,是发展绿色低碳旅游的基础性工作。目前,国内外学者已经从“自下而上”和

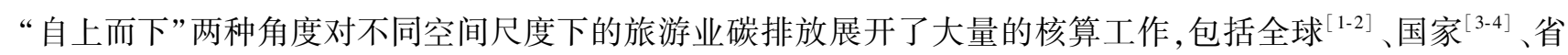
市或地区 ${ }^{[5-6]}$ 以及旅游目的地层面等 ${ }^{[7]}$ 。也有学者基于特定的旅游环节角度进行了碳排放的评估,如旅游交 通 $^{[8]}$ 、旅游住宿 ${ }^{[9-10]}$ 、旅游餐饮 ${ }^{[11]}$ 等。部分学者进一步引入经济指标, 将评估对象转为旅游业碳排放效率, 如 王坤等人依据旅游经济收人 (期望产出) 和碳排放 (非期望产出) 两类产出指标, 测算了中国及各地区的旅游 业碳排放效率 ${ }^{[12]}$; 王凯等则利用空间 Durbin 模型探究了省际旅游业碳排放效率的空间关联特征 ${ }^{[13]}$ 。随着相 关研究的深人, 旅游业碳排放的影响因素研究逐渐引起学者们的关注, 其中因素分解法由于计算过程简便, 并 且可以将特定目标分解成几个易于解释的预定义因素, 逐步成为碳排放研究领域中最热门的分析方法 ${ }^{[14]}$ 。 如陶玉国等利用 LMDI 方法分解了江苏省旅游业碳排放量, 发现游客数量和旅游消费水平的提升助推了旅游 业碳排放的增长, 而能源强度和能耗结构具有一定的抑制作用 ${ }^{[15]}$ 。这与 Liu 等对成都市旅游业碳排放的分 解结果基本一致 ${ }^{[16]}$, 但与 Chen 等对中国旅游业碳排放及其增长率的分解结果有所差异, 他们否定了能源强 度和结构效应的重要分解作用 ${ }^{[17]}$ 。除此之外,也有少数学者引人 STIRPAT 模型 ${ }^{[18]}$ 、数据包络分析与距离函 数 ${ }^{[14]}$ 等其他方法对碳排放的影响因素展开分析。整体来看, 当前有关旅游业碳排放影响机制的研究成果相 对薄弱, 影响因素的选取也多局限于旅游业内部, 对于外部因素的考量明显不足 ${ }^{[19]}$ 。不同于以上研究, 部分 学者从“源-汇”角度出发, 将区域生态系统的碳吸收能力纳人碳排放的研究中, 如梁中等通过界定“碳压力” 概念, 全面评估了区域碳排放与碳承载力之间的平衡关系, 并将碳失衡状态视为 “碳超载” ${ }^{[20]}$; 周年兴等定量 评估了旅游目的地的碳均衡状态, 发现生态系统的固碳量吸收了旅游区碳排放的 $23.47 \%{ }^{[21]}$; 董红艳等综合 比较了江苏省旅游业碳均衡或碳赤字的动态变化情况 ${ }^{[22]}$ 。可以看出, 基于 “源-汇” 视角探究区域旅游业碳均 衡状况的研究思路已经引起了学界的关注,但相关的研究成果尚不充分, 亟待进一步深入探讨。

综上, 现有研究从理论和实证角度对旅游业发展与生态环境的关系进行了丰富而有益的探索, 但研究主 要集中在旅游业碳排放或效率的评估方面, 对于生态系统固碳能力的考量明显不足。在仅有研究中, 由于所 需数据的复杂性, 学者们多从微观或省级层面探讨旅游业碳排放与生态环境的平衡关系, 鲜有文献对全国范 围内的旅游业碳均衡状态进行比较研究, 而有关其作用机制的研究成果仍未见报道。事实上, 厘清各地区旅 游碳赤字现状及区域差异, 并探究其影响机制, 对于明确各地区减排责任、促进生态恢复具有重大意义, 同时 也有助于提高相关政策的针对性和可操作性。为此, 本研究拟构建旅游碳赤字测度模型, 并运用 Theil 指数和 
典范对应分析法等,研究 2008一-2017 年中国旅游业碳均衡情况及其影响因素, 以期弥补已有研究的不足, 丰 富低碳旅游理论体系,并为相关部门制定更具针对性的减排与固碳措施提供数据支撑和理论参考。

\section{1 研究方法与数据来源}

1.1 旅游碳赤字测度模型

\subsection{1 旅游业碳排放}

本文基于“旅游消费剥离系数”将旅游业能耗从与旅游密切相关的行业中剥离出来,再根据排放系数法 计算得到各省市的旅游业排放量 ${ }^{[19]}$ 。目前, 该方法已在旅游业能耗研究中得到了较为广泛的应用 ${ }^{[12]}$ 。

$$
\begin{aligned}
T C & =\sum_{i=1}^{n} \sum_{j=1}^{m}\left(k E_{i t} f_{j}\right) \\
E_{i t} & =E_{i j} \times R_{i} \\
R_{i} & =T_{i} / V_{i}
\end{aligned}
$$

式中, $T C$ 为旅游业总碳排放; $E_{i t}$ 为旅游业能源消耗量; $i$ 表示与旅游密切相关的行业, 即交通运输业、批发和 零售业、住宿和餐饮业、仓储和邮政业等行业; $j$ 表示主要能源种类; $f_{j}$ 为 $j$ 类能源的标准煤转换系数; $k$ 为单位 标准煤的碳排放量, 取值为 $2.45^{[23]} ; E_{i j}$ 为某旅游相关行业的 $j$ 类能源消费量; $R_{i}$ 为某旅游相关行业的旅游消费 剥离系数; $V_{i}$ 为行业总增加值; $T_{i}$ 为该行业的旅游增加值。

\subsection{2 旅游碳承载力}

碳承载力 (碳吸收) 是指区域内植被通过光合作用所能够固定 $\mathrm{CO}_{2}$ 的量 ${ }^{[20]}$ 。旅游碳承载力主要指某一时 段内, 某区域生态系统净吸收旅游经济活动产生 $\mathrm{CO}_{2}$ 的最大能力 ${ }^{[22]}$ 。

在测算省级区域碳承载力情况时,本研究主要考虑区域森林、草地及农田生态系统的固碳能力。

$$
\begin{gathered}
C C=C C_{F}+C C_{G}+C C_{P} \\
C C_{I}=C C_{F}+C C_{G}=\sum M_{I} \times S_{I}
\end{gathered}
$$

式中, $C C$ 为区域碳承载力; $C C_{F}$ 和 $C C_{G}$ 为森林、草地的固碳能力; $C C_{P}$ 为农田的固碳能力 (表 1 ); $M_{I}$ 为第 $I$ 种植 被的面积; $S_{I}$ 为第 $I$ 种植被的年均碳吸收能力, 借鉴国内外专家学者的研究成果, 选取森林碳吸收系数为 3.81 $\mathrm{t} / \mathrm{hm}^{2[24]}$ 、草地碳吸收系数为 $0.21 \mathrm{t} / \mathrm{hm}^{2[25]}$ 。

依据上述公式, 可以计算得到森林、草地以及农田生态系统的固碳能力, 将三者进行加总求和, 便可以得 到区域生态系统的总碳承载力。在此基础上,构建旅游碳承载力的测度模型。区域旅游碳承载能力的测度与 区域旅游业碳排放、区域生态系统碳承载力、以及旅游经济贡献密切相关 ${ }^{[22]}$ 。本文拟根据近年来中国各地区 的旅游业增加值和地区生产总值等相关数据, 测算旅游业对区域经济发展的实际贡献率。然后依据区域旅游 业的经济贡献值,测算和分析区域生态系统的总碳承载力对于旅游业的相应碳抵消量, 即为该区域的旅游碳 承载力。具体如下:

$$
\mathrm{TCC}=C C \times r
$$

式中, TCC 为区域旅游碳承载力; $r$ 为旅游碳承载力系数, 是区域旅游业增加值占地区生产总值的比重。

\subsection{3 旅游碳赤字}

旅游业碳均衡是在综合考虑区域旅游经济发展水平的基础上, 结合当地生态系统的固碳能力, 评价旅游 业对当地环境影响程度的重要指标。目前学界有关旅游业碳均衡的研究成果尚不充分 ${ }^{[21]}$, 本研究对于旅游 业碳均衡状态的评估主要是通过比较旅游业碳排放与旅游碳承载力的差值大小 (即旅游碳赤字) 来反映。这 个差值 (若为正值) 能够表明旅游业碳失衡程度, 是衡量区域旅游发展对全球环境变化影响的重要依据, 也是 当前旅游业应当承担的减排责任。具体计算公式如下:

$$
\mathrm{TCD}=T C-\mathrm{TCC}
$$

式中, $T C$ 为旅游业碳排放; TCC 为旅游碳承载力; TCD 为旅游碳赤字。若旅游业碳排放多于旅游碳承载力, 即 
区域生态系统的总碳承载力对于旅游业的相应碳抵消量都不足以抵消区域内旅游密切相关行业产生的碳排 放, 则该区域旅游碳赤字为正值, 表现为旅游业碳失衡状态, 这表明该区域旅游活动显著促进了气候变暖, 对 当地生态环境产生严重的不利影响; 若旅游业碳排放少于旅游碳承载力,则区域旅游碳赤字为负值, 表明旅游 业实现了碳均衡发展。

表 1 农田固碳核算公式

Table 1 Accounting formula for farmland carbon sequestration

\begin{tabular}{|c|c|c|}
\hline 项目 & 公式 & 公式说明 。 . \\
\hline Items & Formula & Formula description \\
\hline $\begin{array}{l}\text { 农田净固碳 } \\
\text { Net carbon sequestration of farmland }\end{array}$ & $C C_{P}=C C_{V}-C C_{E}$ & $\begin{array}{l}C C_{P} \text { 为农田净固碳量; } C C_{V} \text { 为农田植被总固碳量; } C C_{E} \text { 为农业 } \\
\text { 活动碳排放 }\end{array}$ \\
\hline $\begin{array}{l}\text { 农田植被总固碳量 } \\
\text { Total carbon sequestration of } \\
\text { farmland vegetation }\end{array}$ & $C C_{V}=\sum_{\mathrm{i}=1}^{n} Q_{\mathrm{i}} \times \mathrm{d}_{i} \times\left(1-\mathrm{f}_{i}\right) / E_{i}$ & $\begin{array}{l}Q_{i} \text { 为第 } i \text { 类主要农作物产量; } d_{i} \text { 为第 } i \text { 类主要作物含碳率; } f_{i} \text { 为 } \\
\text { 第 } i \text { 类主要作物水分系数; } E_{i} \text { 为第 } i \text { 类主要作物经济系数, 相 } \\
\text { 关作物系数借鉴专家学者的研究成果 }{ }^{[26]}\end{array}$ \\
\hline \multirow[t]{5}{*}{$\begin{array}{l}\text { 农业活动碳排放 } \\
\text { Carbon emissions from } \\
\text { agricultural activities }\end{array}$} & $C C_{E}=X_{\mathrm{i}}+E_{C}+E_{d}+E_{f}$ & $\begin{array}{l}X_{i} \text { 是农业生产投人碳排放; } E_{c} \text { 表示农业机械使用过程中的碳 } \\
\text { 排放; } E_{d} \text { 为农田灌溉过程中的碳排放; } E_{f} \text { 指农田翻耕破坏土 } \\
\text { 壤有机碳库导致的碳排放 }\end{array}$ \\
\hline & $X_{\mathrm{i}}=\mathrm{q}_{i} \times \lambda_{\mathrm{i}}$ & $\begin{array}{l}i \text { 表示化肥、农药、农膜; } q_{i} \text { 为第 } i \text { 类投人使用量; } \lambda_{i} \text { 为第 } i \text { 类投 } \\
\text { 人每 } \mathrm{kg} \text { 所产生的碳排放 }(\mathrm{kg}) \text {, 分别为 } 0.8956 、 4.9341 \text { 、 } \\
5.18^{[27]}\end{array}$ \\
\hline & $E_{\mathrm{c}}=B \times e+O \times g$ & $\begin{array}{l}B \text { 表示农作物种植面积; } e \text { 为单位面积碳排放系数, 取值 } \\
0.0016 \mathrm{~kg} / \mathrm{m}^{2} ; O \text { 为农业机械总动力 } ; g \text { 为单位机械总动力对 } \\
\text { 应的碳排放 }(\mathrm{kg}) \text {, 取值 } 0.18^{[28]}\end{array}$ \\
\hline & $E_{\mathrm{d}}=Z \times \mathrm{w}$ & $Z$ 为农业灌溉面积; $w$ 是其碳排放系数, 取值 $0.027 \mathrm{~kg} / \mathrm{m}^{2[28]}$ \\
\hline & $E_{\mathrm{f}}=S_{\mathrm{b}} \times P$ & $\begin{array}{l}S_{b} \text { 为农作物 播种面积; } P \text { 是其碳排放系数, 取值 } 0.031 \\
\mathrm{~kg} / \mathrm{m}^{2}[29]\end{array}$ \\
\hline
\end{tabular}

1.2 泰尔 (Theil) 指数

泰尔指数源于信息理论中熵的概念,也称泰尔熵标准,因其具有可分解性,可以明确区域差异结构及差异 来源,已被广泛应用来分析地区碳排放、能源效率等差异 ${ }^{[30]}$ 。本文引人此指数来探究旅游碳赤字的区域差异 特征。

$$
\begin{aligned}
& T=T_{w}+T_{B} \\
& T_{q}=\sum_{i=1}^{n_{q}} \frac{1}{n_{q}}\left(\frac{d_{i}}{\bar{d}_{q}}\right) \ln \left(\frac{d_{i}}{d_{q}}\right) \\
& T_{\mathrm{w}}=\sum_{q=1}^{m} T_{q}\left(\frac{n_{q}}{n} \times \frac{\bar{d}_{q}}{\bar{d}}\right) \\
& T_{\mathrm{B}}=\sum_{q=1}^{m} \frac{n_{q}}{n}\left(\frac{\bar{d}_{q}}{\bar{d}}\right) \ln \left(\frac{\bar{d}_{q}}{\bar{d}}\right)
\end{aligned}
$$

式中, $n_{q}$ 为各地带所包含的省份数量; $n$ 为省份总数; $T_{a}$ 为各地带内旅游碳赤字差异的泰尔指数; $d_{i} 、 \bar{d}_{a}$ 和 $\bar{d}$ 分 别表示各地带内第 $i$ 省的旅游碳赤字、各地带旅游碳赤字均值以及全国旅游碳赤字均值; $T_{W} 、 T_{B}$ 分别表示地 带内、地带间泰尔指数; $T$ 表示旅游碳赤字总体差异的泰尔指数, 取值在 $0-1$ 之间, $T$ 值越大, 表明区域旅游 碳赤字差异越大。

1.3 影响因素选取与分析方法

\subsection{1 影响因素选取}

基于旅游业碳均衡状况变化的复杂性及数据的可获性, 本文从旅游经济、生态环境等维度出发,综合借鉴 
已有研究成果 ${ }^{[17,31-33]}$, 选取指标如下: (1) 旅游接待规模( Tourist Reception Scale, TRS) : 用旅游接待人数来表 征。通常认为, 游客数量越多, 其在食、宿、行、游、购、娱等旅游业要素部门的能耗量也将扩大, 进而影响旅游 业碳均衡。(2) 旅游经济规模 ( Tourism Economic Scale,TES) : 随着旅游产业规模的扩大,一方面旅游业能源 消耗将增多,另一方面旅游业各类要素可能会产生集聚现象,这都可能会影响旅游业碳均衡状态。该指标选 取能反映旅游经济规模的旅游业增加值来表征。(3) 旅游技术水平 (Tourism Technology Level, TEL) : 技术进 步可以降低生产过程中的能耗, 提高行业能源利用效率。该指标以地区旅游业能源强度来表征。(4)旅游资 源禀赋(Endowment of Tourism Resources,TRE) : 区域旅游资源禀赋一定程度上显示了该地区旅游吸引力, 可 能会对旅游规模产生间接影响,继而影响碳均衡状态。参照专家学者的研究成果 ${ }^{[34]}$, 以各地区旅游景区总体 分值来表示。(5)服务业发展水平 (Development Level of Service Industry,SDL) : 旅游业依托于关联服务业,因 而服务业发展水平的高低必然会影响旅游业的发展规模及质量,继而对旅游业碳均衡状态产生影响。该因素 用第三产业增加值来表征。(6)气候环境 (Climatic Environment, $C E$ ) : 适宜的气候条件不仅有助于区域固碳 能力的提高 ${ }^{[35]}$, 也可能会减少企业能耗量 (如耗电量高的酒店行业)。选取降水量 ( (Precipitation, PR) 和气 温( Temperature, $T E$ ) 两个指标, 表征自然环境对旅游业碳均衡的影响。（7) 土地利用结构 (Land Use Structure, LUS ) : 以各省市建设用地占比来表征。一方面, 旅游交通运输是旅游业排放的主要碳源 ${ }^{[36]}$, 而建设 用地规模扩大的同时, 交通用地也会随之增加; 另一方面, 建设用地占比提高, 意味着其他具有固碳功能的林 地、草地等用地将会减少,进而对旅游业碳均衡状态产生影响。(8)生态保护与建设( Ecological Protection and Construction, EPC) : 政府对自然环境和生态保护的支持力度有助于区域碳承载力的提高。选取生态建设与保 护投资总额以表征生态保护与建设力度对旅游业碳均衡的影响。(9)旅游环境规制 ( Tourism Environmental Regulation,TER): 积极而严格的环境政策可以促进科学技术进步,提高资源利用效率,减少资源消耗的排放。 该因素用治污费用与旅游收人的比率来反映 ${ }^{[31]}$ 。

\subsection{2 分析方法}

本文主要运用 $\mathrm{K}$ 均值聚类分析 (K-means cluster) 和典范对应分析法 (Canonical Correspondence Analysis, $\mathrm{CCA}$ ) 探究中国各省域旅游业碳均衡类型分布与影响因子之间的关系, 从而为探寻区域差异化的碳均衡优化 路径提供理论参考。

K-means cluster 是对一组变量或样本进行定量分类的多元统计方法。首先,将旅游碳赤字及其测度的相 关指标数据 (包括旅游业碳排放、旅游碳承载力及旅游碳赤字) 组成数据矩阵, 在此基础上借助 SPSS 软件对 该数据矩阵进行聚类分析, 以探究全国各地区旅游业碳均衡的聚类分组特征。

其次,基于旅游接待规模、旅游经济规模、服务业发展水平、土地利用结构、生态保护与建设、旅游技术水 平、旅游环境规制、旅游资源禀赋和气候环境等各类影响指标的数据矩阵,结合上述聚类分组特征进行典范对 应分析, 以揭示各类指标对旅游业碳均衡类型分布的影响程度。

典范对应分析法是一种数量生态学领域里的限定排序方法, 经由 CA/RA 修改而产生。不同于以前的直 接梯度分析, 它是一种非线性多元梯度的统计分析方法, 可以将对应分析与多元回归结合起来,使样本和环境 因子数据统一起来并进行运算, 其结果能够直观反映各方面信息, 继而更好地表达样本分布与环境因子之间 的关系。有关该方法的具体计算原理可参见张金屯学者的著作 ${ }^{[37]}$ 。

\section{4 数据来源}

本文仅对中国 30 个省市数据进行了统计研究 (因数据获取原因, 尚未统计中国港、澳、台及西藏的数 据)。上述方法所涉及的数据来源主要如下: 其一, 是旅游密切相关行业的能源消费数据, 包含原煤、洗精煤、 型煤、焦炭、焦炉煤气、汽油、煤油、柴油、液化石油气、天然气等十余种能源的终端能源消费量都来自 20092018 年《中国能源统计年鉴》里的各地区能源平衡表; 其二, 是旅游及密切相关行业的经济数据,包括旅游业 人境收人、国内旅游总花费、旅游各类消费的构成比例、第三产业分行业部门增加值与总产出等, 主要来自 2009-2018 年《中国统计年鉴》、各地区统计年鉴、《中国投人产出表》、2009-2018 年《中国旅游统计年鉴》与 
《旅游抽样调查资料》、以及各地区旅游统计公报或者旅游统计便览等; 其三, 是生态系统碳承载力测算的基 础数据, 包括森林和草地的覆盖面积、农作物产量、化肥施用量、农业机械总动力、农业播种面积、灌溉面积等, 主要来源于 2009-2018 年《中国统计年鉴》、各地区统计年鉴、2009-2018 年《中国农村统计年鉴》、EPS 数据 库以及国家自然资源部、林业和草原局等,其余各类测算系数均来自国内外学者的相关研究成果; 其四, 是各 影响指标的基础数据, 主要来源于 2009-2018 年《中国统计年鉴》及各地区统计年鉴、2008-2017 年《中国林 业统计年鉴》、2009-2018 年《中国环境统计年鉴》、中国气象数据网、国家自然资源部以及 EPS 数据库等, 部 分缺失数据采用相邻年份数值进行线性插补, 并利用近五年各指标的均值数据进行典范对应分析。为剔除价 格因素和量纲差异对分析结果的影响,将有关数据统一进行平减及标准化处理。

\section{2 结果分析}

\section{1 中国旅游业碳排放及碳承载力特征}

依据上文所列公式 (1) 至 (6) 可以计算得到中国旅游业碳排放及旅游碳承载力的历年变化情况。由图 1 可知, 2008-2017 年, 中国旅游业碳排放由 20071 万 $\mathrm{t}$ 增加至 54384 万 $\mathrm{t}$, 除个别年份出现下降外, 总体呈现增 长态势。但从选定时段内的变动情况来看, 明显表现为两个阶段: 2008-2012 年全国旅游业碳排放处于高速 增长阶段,年均增长近 16\%;2012-2017 年间旅游业碳排放增速明显放缓, 年均增长率降至 9\%左右。值得注 意的是, 在 2012-2013 年间旅游业碳排放甚至出现了负增长, 这些变化很可能是由于十八大以来, 国家大力 推行 “绿色生态与低碳转型”, 对各类行业尤其是高耗能产业制定了更为严格的 “节能降耗” 约束性指标, 而旅 游业作为第三产业的代表, 也大力推行节能减排, 加快推进产业结构转型升级, 并对部分污染能耗大的旅游企 业实行关停, 继而有效遏制了旅游业碳排放的增长势头。在区域格局方面, 东部地带旅游业碳排放始终处于 主导地位, 在选定时段内占全国的比重保持在 $40 \%$ 以上, 这主要是因为该地带的旅游经济发展迅速, 研究期 内游客数量和经济收人都实现了翻倍增长, 极大地提高了各类旅游活动的能耗量; 中、西部地带的旅游业碳排 放相对较少, 但二者合占总排放的比重逐年上升, 在研究期末已达 $59 \%$, 说明这些区域旅游业的发展对能源 消耗的依赖程度持续上升。总的来看, 各地带对旅游业总碳排放的贡献率大小依次为东部 (45.37\%)>西部 $(28.94 \%)>$ 中部 $(25.67 \%)$, 而按照旅游业碳排放的增速大小可以排序为中部 $(15.81 \%)>$ 西部 $(14.94 \%)>$ 东 部 $(7.96 \%)$ 。

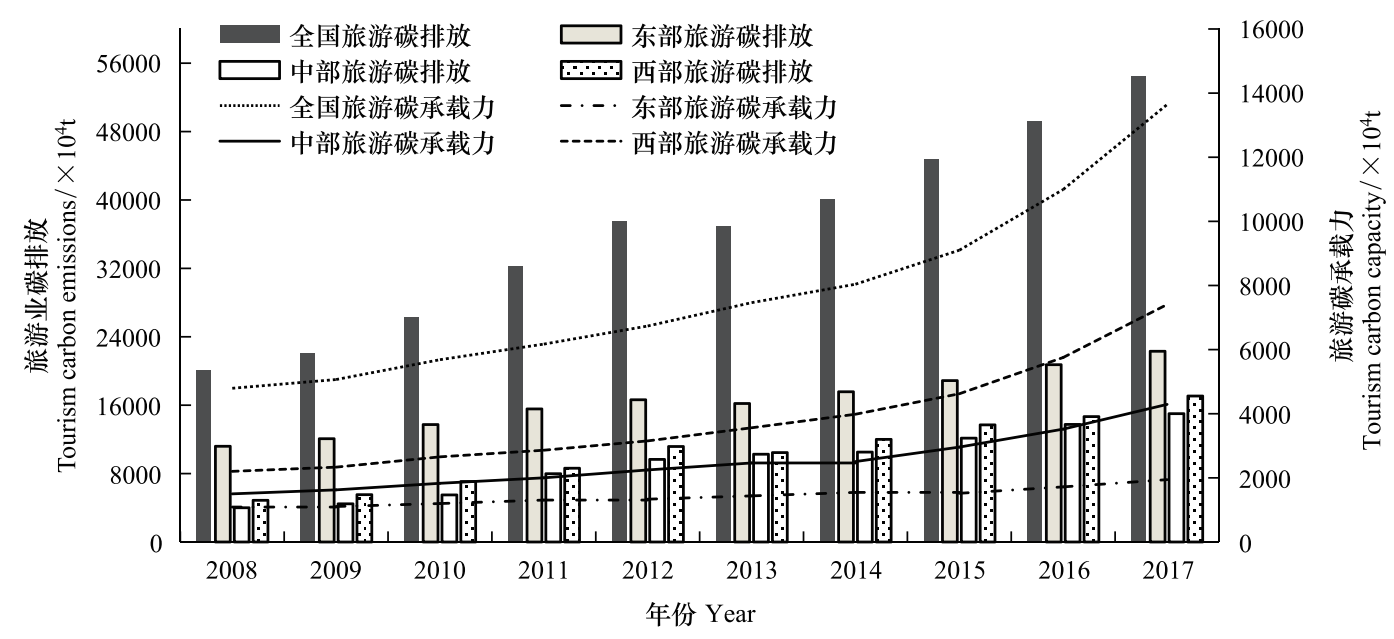

图 12008 - 2017 年中国旅游业碳排放及旅游碳承载力

Fig.1 Carbon emissions and carbon capacity of tourism industry in different regions of China from 2008 to 2017

中国旅游碳承载力在选定时段内始终保持增长态势, 从研究初期 4794 万 $\mathrm{t}$ 上升至期末 13642 万 $\mathrm{t}$, 翻了 近 3 倍,这主要是由于生态系统总体固碳能力的不断提高导致碳承载力的大幅度增加。从研究期的变化情况 
来看, 旅游碳承载力的阶段性特征更加明显。在 2012 年以前, 旅游碳承载力增长相对缓慢, 年均增长仅 $8 \%$ 。 在此之后, 增速明显加快, 到 2017 年增长率高达 $24 \%$,这可能是由于《全国生态保护 “十二五”规划》、《“十三 五”生态环境保护规划》等政策的相继出台,生态环境保护逐步纳人到地区经济与社会发展规划中, “生态文 明建设”也上升为国家战略, 各地区加大对自然生态系统和环境保护的支持力度, 区域森林覆盖率、草原综合 植被盖度等稳步提升, 助推生态系统整体固碳能力和旅游碳承载力进一步提高。通过计算 2008-2017 年东、 中、西部地带旅游碳承载力的平均值, 可以发现, 西部地带旅游碳承载力的贡献最大, 平均占比为 $48.66 \%$, 中 部地带次之, 东部地带最小, 仅 $19.17 \%$, 可见全国旅游碳承载力的地带性差异较为明显。纵向来看, 三大地带 旅游碳承载力均呈现增长的趋势。其中,西部旅游碳承载力增幅最大, 在全国的比重由研究初期 $39 \%$ 增至期 末 $45 \%$ 。同时期该地带旅游碳承载力的增速也提升最快, 由 $6.67 \%$ 上升至 $25.54 \%$, 尤其是 2015 年后呈现加 速增长态势, 到 2017 年增长率上升近 10\%, 这与全国总体发展趋势基本一致。中部地带旅游碳承载力的年均 增长率仅次于西部, 东部地带的年均增速最小。值得注意的是, 东、中部地带的旅游碳承载力在选定时段内虽 保持一定程度的增长, 但所占比重逐年下滑, 到研究期末纷纷跌至平均线以下, 今后仍有较大的固碳空间。

2.2 中国旅游业碳均衡状态及其区域差异特征

旅游碳赤字能够直观反映旅游业碳均衡状态。基于历年旅游业碳排放及旅游碳承载力数值, 结合公式 (7) 可计算得到全国 30 个省市的旅游碳赤字结果, 继而可以对 2008-2017 年全国及各地区的旅游业碳均衡 状态进行评估分析。

2008 - 2017 年全国旅游碳赤字均值分别为 515 万 $\mathrm{t} 、 571$ 万 $\mathrm{t} 、 687$ 万 $\mathrm{t} 、 867$ 万 $\mathrm{t} 、 1024$ 万 $\mathrm{t} 、 982$ 万 $\mathrm{t} 、 1068$ 万 $\mathrm{t} 、 1187$ 万 $\mathrm{t} 、 1272$ 万 $\mathrm{t} 、 1358$ 万 $\mathrm{t}$, 研究期内旅游碳赤字均为正值且呈现波动上升的趋势, 表明旅游业发展始终 处于碳失衡状态, 且碳失衡程度较为严重。同时也反映出我国旅游业减排责任重大,减排形势愈发严峻。就 具体省市而言 (图 2), 北京、辽宁、上海、江苏、浙江、广东等地的旅游碳赤字均值 (1500 万 $\mathrm{t}$ 以上) 位于全国前 列, 而内蒙古、黑龙江、江西、甘肃、青海的平均碳赤字水平低于 400 万 $\mathrm{t}$, 其余地区的碳赤字均值多位于 7001200 万 $\mathrm{t}$ 之间, 可见不同地区的旅游业碳失衡程度差异巨大。究其原因, 可能源于各地区生态一经济环境的 非均质性、旅游资源的空间异质性以及生态环保资金、低碳技术等支持性因素的不平衡性等,导致各地区的旅 游碳赤字存在较大的差异。从研究期内的动态变化情况来看, 安徽、江西、黑龙江、甘肃、青海等地的旅游碳赤 字增长速度最快, 年均增长率都在 $30 \%$ 以上, 而内蒙古、天津、宁夏等地的年均增长率都在 $6 \%$ 以下, 处于全国 旅游碳赤字增速的低值区。其中, 内蒙古在研究期内甚至出现了负增长, 这可能归因于其强大的碳承载能力。 值得一提的是, 东部多数省份 (如北京、上海、江苏、浙江等地) 旅游碳赤字的基数庞大, 但年均增长率呈现出 逐年下降的趋势, 研究期内的增速均值也远低于全国平均水平, 表明其碳失衡程度在未来可能会有所减缓, 今 后减排的重点应逐步扩展至中、西部地带。

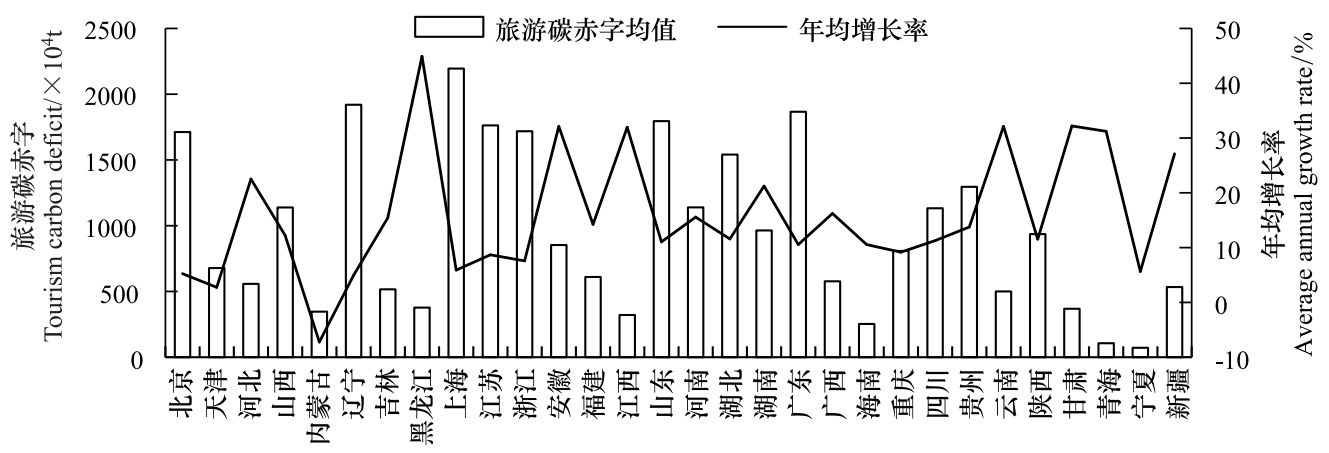

省市 Provinces and cities

图 $22008-2017$ 年各地区旅游碳赤字均值及年均增长率

Fig.2 Mean and annual growth rate of provincial tourism carbon deficit from 2008 to 2017 
运用公式 (8) 至 (11) 计算中国及各地带旅游碳赤字的泰尔指数并进行分解 (表 2), 进一步探究旅游碳赤 字区域差异的变化特征及内在构成。由表 2 可知,2008-2017 年全国旅游碳赤字的泰尔指数呈现 “双 U 型” 波动变化趋势。2008-2012 年间, 总泰尔指数经历了第一个 “U” 型波谷, 并在 2009 年达到十年最高值 0.4382。2012-2013 年泰尔指数小幅增长,随后经过 2015 年的短暂下降,在 2016 年后又呈现增长态势, 可见 该时段处于第二个“U” 型波谷。整体来看,旅游碳赤字的总泰尔指数从研究初期 0.4199 降低至期末 0.1967 , 下降幅度高达 $53.16 \%$, 表明旅游碳赤字的总体差异在选定时段内大幅减小, 这主要是由于旅游碳赤字低值地 区的增长速度相对于旅游碳赤字高值地区较快,进一步减少了旅游碳赤字的总体差异。地带间与地带内的泰 尔指数也呈现下降趋势, 研究期内两者分别减少了 $40.19 \%$ 和 $72.03 \%$, 说明地带间泰尔指数的下降速度远快 于地带内, 旅游碳赤字地带间的差异加速缩小。从各个地带内泰尔指数的变化情况来看, 中部地带泰尔指数 由 2008 年 0.0581 降至 2017 年 0.0240 ,降幅为 $55.88 \%$, 而东部地带泰尔指数的下降幅度与其基本持平,西部 地带降幅最小, 仅 $9.98 \%$ 。中部地带泰尔指数在十年间始终处于各地带的低值区, 西部地带泰尔指数除 2016、 2017 年外也均低于东部, 可见东部旅游碳赤字差异最大,西部次之,中部地带差异最小。

表 $22008-2017$ 年中国旅游碳赤字泰尔指数

Table 2 Theil index of tourism carbon deficit from 2008 to 2017

\begin{tabular}{|c|c|c|c|c|c|c|}
\hline $\begin{array}{l}\text { 年份 } \\
\text { Year }\end{array}$ & $\begin{array}{l}\text { 东部 } \\
\text { Eastern } \\
\text { region }\end{array}$ & $\begin{array}{c}\text { 中部 } \\
\text { Central } \\
\text { region }\end{array}$ & $\begin{array}{c}\text { 西部 } \\
\text { Western } \\
\text { region }\end{array}$ & $\begin{array}{l}\text { 地带内泰尔指数 } \\
\text { Theil index of intra- } \\
\text { regional differences }\end{array}$ & $\begin{array}{l}\text { 地带间泰尔指数 } \\
\text { Theil index of inter- } \\
\text { regional differences }\end{array}$ & $\begin{array}{l}\text { 总体 } \\
\text { Total }\end{array}$ \\
\hline 2008 & 0.1159 & 0.0581 & 0.0748 & 0.2488 & 0.1710 & 0.4199 \\
\hline 2009 & 0.1232 & 0.0705 & 0.0883 & 0.2820 & 0.1562 & 0.4382 \\
\hline 2010 & 0.1100 & 0.0489 & 0.0731 & 0.2320 & 0.1201 & 0.3521 \\
\hline 2011 & 0.0935 & 0.0366 & 0.0676 & 0.1977 & 0.0750 & 0.2726 \\
\hline 2012 & 0.0696 & 0.0266 & 0.0365 & 0.1327 & 0.0394 & 0.1720 \\
\hline 2013 & 0.0758 & 0.0275 & 0.0513 & 0.1547 & 0.0496 & 0.2043 \\
\hline 2014 & 0.0746 & 0.0284 & 0.0524 & 0.1555 & 0.0431 & 0.1986 \\
\hline 2015 & 0.0634 & 0.0186 & 0.0516 & 0.1336 & 0.0373 & 0.1709 \\
\hline 2016 & 0.0563 & 0.0240 & 0.0578 & 0.1381 & 0.0490 & 0.1871 \\
\hline 2017 & 0.0558 & 0.0256 & 0.0674 & 0.1488 & 0.0478 & 0.1967 \\
\hline
\end{tabular}

由表 3 可知,各地带内及地带间的旅游碳赤字差异对总差异的贡献度区别很大。2008-2017 年地带间 差异的贡献度从 $40.74 \%$ 下降至 $24.33 \%$, 同期地带内差异的贡献度保持平稳增加, 且各年度对总差异的贡献 率均超过了 55\%以上, 说明地带内差异较大程度上解释了总体差异, 是造成旅游碳赤字整体差距的主要原 因。从各个地带内差异贡献度的横向对比来看,除 2016 和 2017 年外,东部地带的贡献度始终大于其余两地 带, 表明旅游碳赤字地带内的差异主要根源于东部地带。从纵向变化的情况来看, 研究期内东部、西部地带贡 献度均呈现上升态势, 其中西部贡献度年均增加 7.52\%, 处于加速增长阶段。东部地带贡献度在 2008-2012 年间增长最快, 在 2013 年后开始波动下降, 到 2017 年仅 $28.39 \%$ 。只有中部地带贡献度在研究期末呈现负增 长, 降幅约 5.80\%。可见, 在选定时段内, 旅游碳赤字地带内差异对东部和中部的依赖程度降低,对西部的依 赖程度提升, 并且在 2017 年达到最高值 $34.25 \%$ 。究其原因, 可能是由于近年来西部各省市旅游碳承载力的 抵消效果差距巨大, 进一步加剧了同一地带内旅游碳赤字的差异程度。总体而言, 中国各地区旅游碳赤字总 差异主要来自地带内差异,而地带内差异主要是由东部和西部地带的差异引起的。

\section{3 中国旅游业碳均衡的影响因素分析}

基于旅游业相关碳排放、旅游碳承载力及旅游碳赤字等数据,运用 K-means cluster 对中国 30 个省市进行 快速聚类 (图 3)。其中第 I 类主要包括北京、上海、江苏、浙江、辽宁、山东、湖北、广东 8 个地区,第 II 类包括 天津、福建、吉林、重庆、河北、海南、甘肃、青海、宁夏、新疆 10 个地区、第 III类包括四川、安徽、湖南、贵州、陕 西、山西、河南 7 个地区,第 $\mathrm{V}$ 类包括内蒙古、黑龙江、江西、广西、云南 5 个地区。 
表 $32008-2017$ 年旅游碳赤字总差异的分解

Table 3 Decomposition of the total difference in the tourism carbon deficit from 2008 to 2017

\begin{tabular}{|c|c|c|c|c|c|}
\hline \multirow{2}{*}{$\begin{array}{l}\text { 年份 } \\
\text { Year }\end{array}$} & \multirow{2}{*}{$\begin{array}{c}\text { 地带内贡献率 } \\
\text { Intra-regional } \\
\text { contribution rate/\% }\end{array}$} & \multicolumn{3}{|c|}{$\begin{array}{c}\text { 各地带贡献率 } \\
\text { Contribution rate of each region/\% }\end{array}$} & \multirow{2}{*}{$\begin{array}{c}\text { 地带间贡献率 } \\
\text { Inter-regional } \\
\text { contribution rate/\% }\end{array}$} \\
\hline & & $\begin{array}{c}\text { 东部 } \\
\text { Eastern region }\end{array}$ & $\begin{array}{c}\text { 中部 } \\
\text { Central region }\end{array}$ & $\begin{array}{c}\text { 西部 } \\
\text { Western region }\end{array}$ & \\
\hline 2008 & 59.26 & 27.61 & 13.83 & 17.82 & 40.74 \\
\hline 2009 & 64.36 & 28.12 & 16.10 & 20.14 & 35.64 \\
\hline 2010 & 65.90 & 31.26 & 13.88 & 20.76 & 34.10 \\
\hline 2011 & 72.50 & 34.28 & 13.41 & 24.81 & 27.50 \\
\hline 2012 & 77.12 & 40.48 & 15.46 & 21.19 & 22.88 \\
\hline 2013 & 75.71 & 37.12 & 13.48 & 25.10 & 24.29 \\
\hline 2014 & 78.29 & 37.57 & 14.30 & 26.41 & 21.71 \\
\hline 2015 & 78.20 & 37.08 & 10.89 & 30.22 & 21.80 \\
\hline 2016 & 73.80 & 30.09 & 12.81 & 30.90 & 26.20 \\
\hline 2017 & 75.67 & 28.39 & 13.03 & 34.25 & 24.33 \\
\hline
\end{tabular}

从表 4 可以看出,第 I 组类型区旅游业碳排放最 高, 而旅游碳承载力相对较低, 总体表现为高碳赤字水 平, 旅游业碳失衡程度最为严重。虽然该组类型区内多 数省份的旅游业碳排放增速偏低,但排放基数庞大(如 北京、上海、江苏、浙江、广东等地),已经对当地生态环 境造成了严重的不利影响,今后该组类型区应积极承担 相应的减排责任。处于 “低排放、低承载力、低赤字” 的 地区主要有天津、甘肃、青海、宁夏等地,这些地区都属 于第 II 组类型区,整体表现为一般的碳失衡状态, 旅游 业减排责任相对较轻。第 III 组类型区 (主要分布于中、 西部) 旅游业碳排放也处于高值区,但该类型区具有一 定的碳承载力发展空间,在一定程度上能够抵消部分碳 排放,属于旅游碳赤字较高区, 旅游业碳失衡程度较为 严重。值得一提的是, 在旅游碳承载力的抵消作用上, 第IV类地区平均碳抵消效果达到了 $70 \%$ 以上,远超过 其余三类地区。究其原因, 主要是由于这些地区 (内蒙

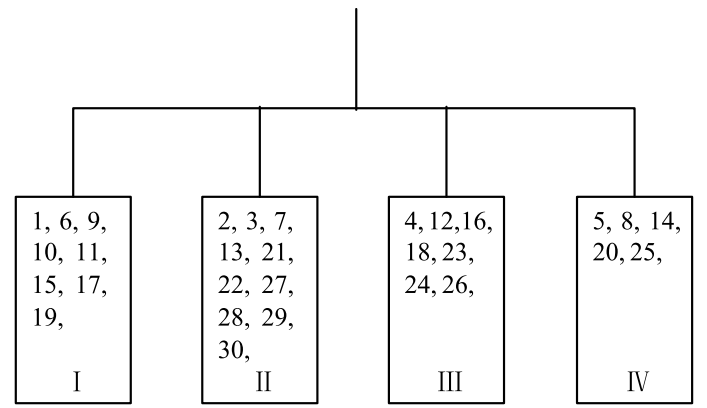

图 3 旅游碳赤字测算指标的聚类结果

Fig.3 Clustering results of tourism carbon deficit measurement indicators

各省市序号及名称: 1 北京, 2 天津, 3 河北, 4 山西, 5 内蒙古, 6 辽 宁, 7 吉林, 8 黑龙江, 9 上海, 10 江苏, 11 浙江, 12 安徽, 13 福建, 14 江西, 15 山东, 16 河南, 17 湖北, 18 湖南, 19 广东, 20 广西, 21 海南,22 重庆,23 四川,24 贵州,25 云南,26 陕西,27 甘肃,28 青 海, 29 宁夏, 30 新疆 古、黑龙江、云南等) 依托其本身的自然资源优势, 可以 产生持续稳定的碳承载力环境,继而有效补偿了旅游业的主要碳源。总的来看,第 II 组和第 IV 组类型区的旅 游业碳失衡程度相对较轻, 整体处于一般的旅游业碳失衡状态, 若相关部门加大对 “绿色生态与低碳转型” 等 方面的支持力度,这些区域有望率先实现旅游业碳均衡,减少对气候变化的影响。第 I 组和第 III 组类型区的 旅游业总体表现为严重的碳失衡状态,减排形势不容乐观,今后应积极承担相应的减排责任。

表 4 旅游碳赤字测算指标的差异

Table 4 The differences of tourism carbon deficit measurement indicators

\begin{tabular}{cccc}
\hline & $\begin{array}{c}\text { 旅游业碳排放 } \\
\text { Tourism carbon emissions }\end{array}$ & $\begin{array}{c}\text { 旅游碳承载力 } \\
\text { Tourism carbon capacity }\end{array}$ & $\begin{array}{c}\text { 旅游碳赤字 } \\
\text { Tourism carbon deficit }\end{array}$ \\
\hline 第 I 类 Type I & 1.339 & 0.141 & 0.859 \\
第 II 类 Type II & 0.440 & 0.119 & 0.238 \\
第 III 类 Type III & 1.169 & 0.349 & 0.576 \\
第IV 类 Type IV & 0.835 & 0.613 & 0.238 \\
\hline
\end{tabular}


通过观察不难发现 (图 4), 不同类型均分布在一定的空间区域,其中第 II 类和第IV类集中分布在第三、四 象限,第 III类集中分布在第二象限,第 I 类则主要分布在第一象限。相近的类型区有交叉分布的现象,不相近 的类型区则彼此之间有一定的距离,说明典范对应分析图 (CCA 图) 能够有效地呈现出各组样本分布与影响 因子之间的关系。首先, 旅游接待规模、旅游经济规模、土地利用结构、生态保护与建设、旅游技术水平的连线 相对较长, 说明这些因子是影响样本分布的主要因素。第二, 各因子与排序轴的夹角代表它们之间相关性的 大小, 如土地利用结构、旅游资源禀赋、生态保护与建设、旅游环境规制与第一排序轴关系极为密切, 旅游技术 水平、降水与第二排序轴的相关性较高。第三, 各影响因子与排序轴的关系也可用典范系数和相关系数 (表 5) 来表示, 如图中土地利用结构与第一排序轴的夹角极小,与第二轴相距较远,说明该因子与第一轴的相关 性远大于第二轴, 这与典范系数表中的结果相一致。另外从表 5 也可以明显看出, 第一排序轴与旅游技术水 平、旅游环境规制、生态保护与建设呈负相关, 说明沿着第一轴自左向右这 3 种因子的数值呈现递减的态势。 而第二排序轴与旅游经济规模、旅游技术水平、服务业发展水平等相关性较大, 表明自下而上这些影响因子均 表现出增加的态势。总体来看, 在各类因素的综合作用下, 从左下角至右上角, 各组类型呈现出由一般碳失衡 类型区逐步向严重碳失衡类型区过渡的趋势, 具有显著的“弓形效应” ${ }^{[37]}$ 。

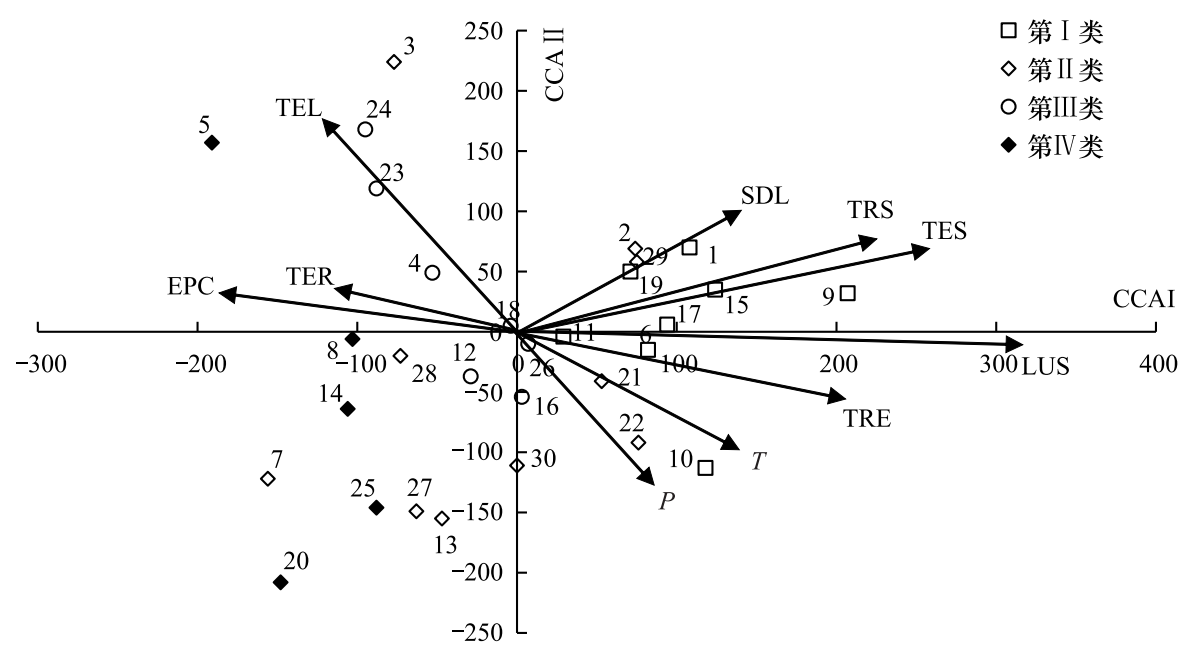

图 4 中国旅游业碳均衡的典范对应分析图

Fig.4 Canonical correspondence analysis figure of tourism carbon equilibrium in China

(1)各省市序号及名称同图 3; 2TRS: 旅游接待规模; TES: 旅游经济规模; TEL: 旅游技术水平; TRE: 旅游资源亭赋; SDL: 服务业发展水平; $\mathrm{TE}$ :气温; PR: 降水;LUS: 土地利用结构; TER : 旅游环境规制; EPC:生态保护与建设

基于各组类型区的递变趋势, 可以识别出影响旅游业碳失衡程度的正负向因子。其中,位于第一象限的 北京、上海、浙江、山东、湖北、广东等地主要受旅游经济规模、旅游接待规模、服务业发展水平的正向影响,这 些地区的旅游业及关联服务业发展迅速, 不仅提高了当地的旅游影响力, 还丰富了旅游服务或产品组合的供 给, 助推具有 “娱乐性” 或 “强体验性” 的高排放、高能耗旅游服务产品的不断涌现, 继而加重了地区的碳失衡 程度。土地利用结构对旅游碳赤字也具有一定的正向作用, 尤其是对于上海、辽宁、浙江、湖北等地的影响更 为明显, 这些地区具有固碳功能的用地占比较小, 增汇能力相对薄弱, 而地区交通基础设施和服务设施的建设 也会进一步提升旅游接待能力, 助推旅游规模及能源消耗的增加, 继而间接加剧了旅游业碳失衡程度。位于 第四象限的海南、陕西、重庆等地主要受旅游资源禀赋和气候环境的影响,其中气候环境呈现出一定的负向作 用, 而旅游资源禀赋主要表现为正向影响, 但两者的综合影响能力均不显著。旅游技术水平为负向指标, 其对 旅游碳赤字的抑制作用较为突出, 尤其对于山西、贵州、四川、内蒙古等地, 这些地区旅游业发展所积累的环境 问题以及受到技术更新的时滞性影响, 导致单位旅游产出的能耗较高, 能源利用效率有待提升, 若及时采取措 施以降低能源强度, 将会有效缓解区域碳失衡程度。位于第二、三象限的福建、吉林、内蒙古、黑龙江、江西、广 
西、云南等地的旅游碳赤字主要受生态保护与建设、旅游环境规制的负面影响,这些地区大多具有先天的生态 恢复条件,政府生态保护力度的加强能够进一步促进当地生态系统固碳能力的提高。另外,适当的环境规制 也能够对高排放旅游企业的行为形成约束,倒逼其实施技术创新以弥补额外的环境成本。总体而言,旅游接 待规模、旅游经济规模、服务业发展水平及土地利用结构 4 个影响因子会加剧旅游业碳失衡程度,生态保护与 建设、旅游技术水平、旅游环境规制能够起到一定的限制作用,而旅游资源禀赋和气候环境 2 个因子的正负向 影响均不明显。基于各地区情况的差异, 相关部门应在统筹考虑各类因子的基础上尽快制定区域差异化 策略。

表 5 各排序轴与影响因子的关系

Table 5 The relationship between the ordination axes and the influencing factors

\begin{tabular}{|c|c|c|c|c|}
\hline \multirow{2}{*}{$\begin{array}{l}\text { 影响因子 } \\
\text { Influencing factors }\end{array}$} & \multicolumn{2}{|c|}{$\begin{array}{c}\text { 典范系数 } \\
\text { Canonical coefficient }\end{array}$} & \multicolumn{2}{|c|}{$\begin{array}{c}\text { 相关系数 } \\
\text { Correlation coefficient }\end{array}$} \\
\hline & CCA I & CCA II & CCA I & CCA II \\
\hline 旅游接待规模 Tourist reception scale & 0.264 & 0.075 & 0.227 & 0.079 \\
\hline 旅游经济规模 Tourism economic scale & 0.358 & 0.100 & 0.303 & 0.126 \\
\hline 旅游技术水平 Tourism technology level & -0.184 & 0.222 & -0.182 & 0.260 \\
\hline 旅游资源亭赋 Endowment of tourism resources & 0.247 & -0.049 & 0.160 & -0.038 \\
\hline 服务业发展水平 Development level of service industry & 0.155 & 0.114 & 0.514 & 0.125 \\
\hline 气温 Temperature & 0.224 & -0.143 & 0.290 & -0.169 \\
\hline 降水 Precipitation & 0.122 & -0.186 & 0.112 & -0.267 \\
\hline 土地利用结构 Land use structure & 0.689 & -0.013 & 0.765 & -0.014 \\
\hline 旅游环境规制 Tourism environmental regulation & -0.116 & 0.031 & -0.129 & 0.038 \\
\hline 生态保护与建设 Ecological protection and construction & -0.223 & 0.038 & -0.279 & 0.045 \\
\hline
\end{tabular}

\section{3 结论与讨论}

本研究的主要结论如下:

(1)2008一-2017 年,中国旅游业碳排放及旅游碳承载力整体呈现增长趋势,但旅游业碳排放远高于碳承 载力, 导致全国旅游碳赤字均值由研究初期 515 万 $\mathrm{t}$ 迅速上升至期末 1358 万 $\mathrm{t}$, 旅游业发展始终处于碳失衡 状态, 且碳失衡程度愈发严重。分省市而言,各地旅游业碳均衡发展情况存在较大的差异,除内蒙古、黑龙江、 江西、甘肃、青海等地外, 其余多数省份的碳失衡程度较为严重, 泰尔指数也进一步验证了旅游碳赤字的区域 差异性,但这种差异有进一步缩小的趋势。

(2) 依据 K-means cluster 将全国 30 个省市划分为旅游业碳排放最低型、旅游碳承载力最高型、旅游碳赤 字较高型、旅游碳赤字最高型四组类型，不同类型在典范对应分析图 (CCA 图) 中的空间分布情况差异明显。 CCA 第一轴主要受土地利用结构、旅游资源禀赋、生态保护与建设、旅游环境规制的影响,第二轴主要受旅游 技术水平等因素的影响。基于这些因素的综合作用,从左下角至右上角, 各组样本分布呈现出由一般碳失衡 类型区逐步向严重碳失衡类型区过渡的趋势。

(3) 典范对应分析的结果显示,旅游接待规模、旅游经济规模、旅游技术水平、土地利用结构、生态保护与 建设等是影响旅游业碳均衡状态变化的重要影响因素。其中,旅游接待规模、旅游经济规模、服务业发展水平 及土地利用结构的负面影响较大, 进一步加剧了旅游业碳失衡程度, 而生态保护与建设、旅游技术水平和旅游 环境规制等因素能够对碳失衡状态起到一定的缓解作用。各因素对旅游业碳均衡状态的作用效应具有一定 的空间异质性,可据此制定差异化的碳均衡优化路径。

本文借助旅游、生态等学科的理论基础,构建了较为完善的旅游碳赤字测算模型,继而对 2008一-2017 年 中国旅游业碳均衡状态及其区域差异进行比较与分析, 这不仅克服了已有旅游业碳排放研究中大多未考虑生 态系统固碳能力的局限 ${ }^{[3-4]}$, 而且丰富了较大尺度范围内旅游业碳均衡的理论研究, 同时也有助于综合考虑 
全国旅游业碳减排压力,进一步明确旅游业应当承担的减排责任。对于旅游业减排责任,以往研究多是基于 旅游业碳排放的估算值来展开 ${ }^{[18-19]}$, 并将地区旅游业碳排放量与减排责任直接挂钩,忽视了生态系统强大的 碳承载能力能够补偿部分旅游业碳源这一关键事实,所以以往关于旅游业减排责任衡量方法的科学性有待商 榷。旅游业作为享乐型的第三产业,其核心机制就是资源消耗满足人的主观需求,因此其成为一个碳排放部 门存在自然合理性,但这并不意味着旅游业没有减排责任,其责任就是在考虑生态系统固碳能力对旅游业碳 抵消的作用后, 仍然剩余的旅游业净碳排放量, 即旅游碳赤字。这也意味着, 旅游业应在生态系统所能提供的 碳抵消量的限度内进行碳均衡发展,而非无节制地消耗能源, 更不是推行“零碳”经济。

在旅游业碳均衡的影响因素方面, 目前学术界还未见相关的研究报道, 仅有部分学者对旅游业碳排放或 生态系统碳吸收的影响机制进行了初步探讨 ${ }^{[17,32]}$, 且多局限于 “规模一技术一结构” 的分析框架 ${ }^{[19]}$ 。为了弥 补此不足, 本文的研究设计是在充分考虑前人研究成果和数据可获得性的基础上, 选取影响旅游业碳排放或 生态系统碳吸收的 9 个内外部因素来展开。通过利用聚类分析和典范对应分析方法探究了旅游业碳均衡类 型分布与各影响因子之间的关系, 实现了对旅游业碳均衡作用机制较为全面的考量。此外, 以往关于碳排放 或碳吸收影响机制的研究方法已经相对成熟, 因素分解法 ${ }^{[15-17]}$ 、STIRPAT 模型 ${ }^{[18]}$ 、VAR 模型 ${ }^{[32]}$ 等得到了较 为广泛的应用,但是这些方法大多未能实现各影响因子在空间层面上的直观表达。典范对应分析方法的应 用, 可以将各组样本与影响因子完整结合起来并表达在简化的空间中, 有助于揭示各类因子对不同类型区域 旅游业碳均衡的作用效应, 为各地区减少碳赤字指明更加具体的方向。可以说, 这种研究路径与方法是本研 究区别于其他研究的优势所在。

依据本研究的分析结果与各地区实际情况, 可提出区域差异化的碳均衡优化路径。具体来看: 经济发达 的高碳赤字区 (包括北京、上海、江苏、浙江、山东、广东等地) 大多旅游业及关联服务产业的规模雄厚, 这些产 业在发展的过程中往往伴随着较高的碳排放, 然而促进地区旅游业的发展是惠及民生福祉的重要举措, 这就 要求在日益严峻的减排形势下需要充分发挥自身资金、技术的比较优势,加大对生态保护、低碳技术研发等的 支持力度, 并鼓励低碳、生态型旅游产品的开发设计, 着力优化旅游产品的供给端, 进一步促进旅游业及整个 关联服务产业的转型升级。另外, 土地利用结构的优化也可作为今后减排的重点。森林是碳总蓄积的主 体 ${ }^{[20]}$, 可以适当增加更新造林面积, 合理控制建设用地的规模。而对于山西、贵州、四川、内蒙古等受旅游技 术水平及旅游环境规制影响较大的地区, 一方面应积极寻求发达地区的合作, 重点引进先进的低碳技术, 着力 提升能源利用效率, 改善行业能源利用结构,进一步推动节能减排工作的开展; 另一方面政府应发挥环境规制 的作用, 合理控制 “高排放” 旅游饭店、旅游购物点或娱乐场所的规模 ${ }^{[17]}$, 提高旅游业低碳发展质量, 尽快摆 脱过度依赖资源的困境。针对天津、青海、宁夏、重庆这些“低排放、低固碳、低赤字”的地区,固然当前面临的 减排压力较小, 但考虑到长期影响, 也应积极调控旅游行业的发展, 进一步实现碳减排。对于福建、吉林、内蒙 古、黑龙江、江西、广西、云南等地, 应继续扩大生态保护与建设投资,进一步促进生态系统固碳功能的恢复与 提高。同时尽快制定科学合理的环境规制政策, 不仅可以规范旅游企业的行为, 还可以提高游客低碳行为实 践的意识与能力,促使旅游供给与需求方都向低碳化方向转变。

直于数据可得性, 本研究对于旅游业碳排放、旅游碳承载力的测算多基于一个固定的测算系数, 较少深人 到中国各地区层面, 无法反映出全国不同地区旅游业碳排放、碳承载力测算系数的具体差异以及这些测算系 数的年际变化, 这也一定程度上造成了研究结果与实际情况的偏差。在未来研究中, 可以进一步挖掘和搜集 数据, 深人全国各地区测算符合当地实际的系数值, 以更加客观地反映出全国各地区旅游业碳排放、生态系统 碳承载力的发展情况,并对全国旅游业碳均衡的演变趋势有一个更为精确的认识。

\section{参考文献( References) :}

[ 1 ] Lenzen M, Sun Y Y, Faturay F, Ting Y P, Geschke A, Malik A. The carbon footprint of global tourism. Nature Climate Change, 2018, 8( 6) : 522-528.

[ 2 ] Gössling S. Global environmental consequences of tourism. Global Environmental Change, 2002, 12(4) : 283-302. 
[ 3 ] 石培华, 吴普. 中国旅游业能源消耗与 $\mathrm{CO}_{2}$ 排放量的初步估算. 地理学报, 2011, 66(2): 235-243.

[ 4 ] Luo F, Moyle B D, Moyle C L J, Zhong Y D, Shi S Y. Drivers of carbon emissions in China's tourism industry. Journal of Sustainable Tourism, $2020,28(5): 747-770$.

[ 5 ] Tang M W, Ge S Z. Accounting for carbon emissions associated with tourism-related consumption. Tourism Economics, 2018, 24( 5) : 510-525.

[ 6 ] Yu L, Bai Y P, Liu J M. The dynamics of tourism's carbon footprint in Beijing, China. Journal of Sustainable Tourism, 2019, 27 (2) : 1553-1571.

[ 7 ] Kuo $\mathrm{N} \mathrm{W}$, Chen P H. Quantifying energy use, carbon dioxide emission, and other environmental loads from island tourism based on a life cycle assessment approach. Journal of Cleaner Production, 2009, 17(15) : 1324-1330.

[ 8 ] Luo F, Becken S, Zhong Y D. Changing travel patterns in China and 'carbon footprint' implications for a domestic tourist. Tourism Management, 2018, 65: 1-13.

[ 9 ] Díaz Perez F J, Chinarro D, Mouhaffel A G, Martin R D, Otin M R P. Comparative study of carbon footprint of energy and water in hotels of Canary Islands regarding mainland Spain. Environment, Development and Sustainability, 2019, 21(4) : 1763-1780.

[10］沈杨, 胡元超, 施亚岗, 张千湖, 张红梅, 崔胜辉. 城市酒店业的碳排放核算及低碳指标分析. 环境科学学报, 2017, 37(3): 1193-1200.

[11] Gössling S, Garrod B, Aall C, Hille J, Peeters P. Food management in tourism: reducing tourism's carbon 'foodprint'. Tourism Management, $2011,32(3): 534-543$.

[12］王坤，黄震方，曹芳东. 中国旅游业碳排放效率的空间格局及其影响因素. 生态学报, 2015, 35(21)：7150-7160.

[13] 王凯, 邵海琴, 周婷婷, 刘浩龙. 中国旅游业碳排放效率及其空间关联特征. 长江流域资源与环境, 2018, 27(3): 473-482.

[14] Zha J P, Tan T, Yuan W W, Yang X J, Zhu Y. Decomposition analysis of tourism $\mathrm{CO}_{2}$ emissions for sustainable development: a case study of China. Sustainable Development, 2020, 28(1) : 169- 186.

[15］陶玉国, 黄震方, 吴丽敏, 余凤龙, 王坤. 江苏省区域旅游业碳排放测度及其因素分解. 地理学报, 2014, 69(10): 1438-1448.

[16] Liu J, Feng T T, Yang X. The energy requirements and carbon dioxide emissions of tourism industry of Western China: a case of Chengdu city. Renewable and Sustainable Energy Reviews, 2011, 15(6): 2887-2894.

[17] Chen J D, Zhao A F, Zhao Q P, Song M L, Baležentis T, Streimikiene D. Estimation and factor decomposition of carbon emissions in China's tourism sector. Problemy Ekorozwoju, 2018, 13(2): 91-101.

[18] 王凯, 郡海琴, 周婷婷, 刘浩龙. 基于 STIRPAT 模型的中国旅游业碳排放影响因素分析. 环境科学学报, 2017, 37(3): 1185-1192.

[19］黄和平, 乔学忠, 张瑾, 李亚丽, 曾永明. 绿色发展背景下区域旅游业碳排放时空分异与影响因素研究一以长江经济带为例. 经济地 理, 2019, 39(11): 214-224.

[20］梁中, 徐蓓. 中国省域碳压力空间分布及其重心迁移. 经济地理, 2017，37(2)：179-186.

[21］周年兴, 黄震方, 梁艳艳. 庐山风景区碳源、碳汇的测度及均衡. 生态学报, 2013, 33(13)：4134-4145.

[22］董红艳, 刘钦普, 周丽, 余子萍. 江苏省旅游业碳足迹与碳承载力动态对比分析. 生态经济, 2018, 34(11): 183-187.

[23] 陈飞, 诸大建. 低碳城市研究的理论方法与上海实证分析. 城市发展研究, 2009, 16(10): 71-79.

[24]谢鸿宇, 陈贤生, 林凯荣, 胡安炎. 基于碳循环的化石能源及电力生态足迹. 生态学报, 2008, 28(4): 1729- 1735.

[25] 方精云, 郭兆迪, 朴世龙, 陈安平. 1981-2000 年中国陆地植被碳汇的估算. 中国科学 D 辑: 地球科学, 2007, 37(6)：804-812.

[26] 翁翎燕, 朱振宇, 韩许高, 谈俊忠. 江苏省农田植被净碳汇时空格局分析. 农业工程学报, 2018, 34(6) : 233-241.

[27] 田云, 李波, 张俊运. 我国农地利用碳排放的阶段特征及因素分解研究. 中国地质大学学报: 社会科学版, 2011, 11(1): 59-63.

[28] West T O, Marland G. A synthesis of carbon sequestration, carbon emissions, and net carbon flux in agriculture: comparing tillage practices in the United States. Agriculture, Ecosystems \& Environment, 2002, 91(1/3): 217-232.

[29］伍芬琳, 李琳, 张海林, 陈阜. 保护性耕作对农田生态系统净碳释放量的影响. 生态学杂志, 2007, 26(12) : 2035-2039.

[30］谭华云, 许春晓, 董雪旺. 旅游业碳排放效率地区差异分解与影响因素探究. 统计与决策, 2018, 34(16): 51-55.

[31] Qiu X P, Fang Y P, Yang X T, Zhu F B. Tourism eco-efficiency measurement, characteristics, and its influence factors in China. Sustainability, 2017, 9(9): 1634.

[32] Wu S N, Li J Q, Zhou W M, Lewis B J, Yu D P, Zhou L, Jiang L H, Dai L M. A statistical analysis of spatiotemporal variations and determinant factors of forest carbon storage under China's Natural Forest Protection Program. Journal of Forestry Research, 2018, 29(2) : 415-424.

[33］李波, 刘雪琪, 王昆. 中国农地利用结构变化的碳效应及时空演进趋势研究. 中国土地科学, 2018, 32(3): 43-51.

[34] 马晓龙. 中国主要城市旅游效率及其全要素生产率评价: 1995-2005[D]. 广州: 中山大学, 2008.

[35] Zhang J, Liu M Y, Zhang M M, Yang J H, Cao R S, Malhi S S. Changes of vegetation carbon sequestration in the tableland of Loess Plateau and its influencing factors. Environmental Science and Pollution Research, 2019, 26(22): 22160-22172.

[36] Prideaux B, Yin P. The disruptive potential of autonomous vehicles ( AVs) on future low-carbon tourism mobility. Asia Pacific Journal of Tourism Research, 2019, 24(5): 459-467.

[37] 张金屯. 数量生态学. 北京: 科学出版社, 2004: 171- 178. 